more and more absorbed, when I followed them to some five or more degrees from the sun, in whose proximity they always brightened most, but passing over its disc, appeared to be rather dark, changing, however, suddenly into white when they emerged and entered the blue again. It became obvious that the little bodies I had before me were of small density, partly opaque, apparently of a white and reflecting surface, the edges of which were lit up by the sunbeams.

The course of the higher ones (at some r,00o metres distance) being generally parallel, and their reciprocal velocity of about the same rate, I noticed much variety in the lower strata, where their flight was often of great inconstancy, changing their direction every moment, or falling, and second after second augmenting their focal distance, by the change of which, taken on the eye-piece scale; I learned that these bodies did not quite follow the law of gravitation, losing time; a fact not surprising to me, already convinced of their small consistency. In comparing the daily direction with the simultaneous course of winds and clouds, there was a remarkable conformity. Accepting the direction of the clouds to be the same as that of the wind in the stratum they pass through, a supposition not far from the truth, to which, of course, I was forced, having no weather-cock in such high regions, I found the direction of the little bodies and the clouds (in about the same stratum) to be (I) accurately the same in 3 I per cent. ; (2) differing not above go degrees in 49 per cent.; (3) differing not above 180 degrees in 67 per cent. ; and (4) of quite opposite direction in only $1 \frac{1}{2}$ per cent. This conformity is so evident that when the sky is cloudless, starting from the distance and direction of the ever-passing little bodies, one might easily learn the direction and perhaps the velocity of winds in the reciprocal strata, a fact of course of no little value to meteorologists and even mariners.

Taken altogether, these results could not but lead to the opinion that what I had to deal with were ice-crystals and flakes of snow. Here it may be recollected that already, in the seventeenth century, Mariotte, the renowned discoverer of the law of gas-expansion, pointed out that parhelions and mock-moons are caused by icecrystals floating in the sky; and indeed, if we consider the above results, we are forced to believe him. Firstly, we learned that these bodies belong to the atmosphere; we also found them in its lower strata. Their average size of 32 millimetres, their flake-like shape, their incalculable number, will also strongly convince us. But while the minimum during the winter months might seem rather unaccountable, the chief maximum occurring in April and May, it may be remarked that from September to March the sun, although in the meridian, does not light up so strongly the rather misty sky; and that many days the sun will not appear at all. Now, referring to the chief maximum, from about April 20 to May I5, is it not astonishing that it occurs on the very same days which, especially those of May, were at all times well known from their low temperature, and called in Germany "the Latins" (Pancratius, May I2; Servatius, May 13, \&c.), and were much feared by gardeners? But are the enormous masses of ice-crystals found in the atmosphere during these days the origin of its low temperature, or does the latter favour the formation of snow-masses? I only mention the fact that, for instance, heat is absorbed when snow is melting, and would be happy to direct the attention of meteorologists in any country to this phenomenon, inviting contributions of facts and correspondence. Finally, the velocity of the bodies being the same as that of the clouds, their reflected magnificent white light, their regular courses in the higher regions where strong winds are generally blowing, their irregular or even falling movement and small density in the lower ones, and their very remarkable conformity of direction with simultaneously passing clouds, will give much support to my explanation.

Weinheim, near Heidelberg

\section{THE MONGOOSE AND THE COBRA}

$\mathrm{T} N$ reading the interesting account of a fight between these two animals, as given in NATURE for Jan. II (p. 204), the question arises, How does the mongoose survive the bite of the cobra? There are only two solutions of this question, viz.:-(I) That the mongoose has some antidote; and (2) that it is not affected by the cobra poison. With regard to the first, various observers give different antidotes, such as grass, Aristolochia, \&c. (see Sir J. E. Tennent's "Natural History of Ceylon," p. 38). There is ro one plant that the mongoose has been proved to go to as a remedy. 2. That the mongoose is not poisoned by the bite of the cobra has, I think, been. proved by Dr. Fayrer, of Calcutta. I quote three of his experiments, which are published in the Edinburgh Medical Fournal, April 1869, pp. 917-919:- "A young mongoose (Herpestes Malacconsis) was bitten two or three times by a full-grown cobra, ${ }^{8}$ at 1.24 P.M. on the 30 th April I 868 , on the inner side of the thigh from which the hair was irst removed. Blood was drawn by the bites." This animal died in six minutes, but in the two following experiments no harm resulted to the mongoose. The second mongoose was also "bitten on the inner side of the thigh, and put into a cage immediately." It got no antidote except "raw meat," and was none the worse for the bite. The third mongoose was put into a large wire cage with a full-sized cobra at I P.M. (April 2, 1868). "The snake struck at the mongoose, and they grappled with each other frequently, and apparently the mongoose must have been bitten, as the snake held on to it about the neck or head. At I.I 5 P.M. there was no effect on the mongoose; both it and the snake were much excited and angry, the snake hissing violently. 2.30; no effect on the mongoose. The snake is bitten about the head, and shows the bleeding wounds. $2.5 \mathrm{I}$; they are both occasionally darting at each other, but the mongoose jumps over the snake, and tries to avoid it. Next day at noon both were well; the snake frequently struck at the mongoose, but did not appear to injure it; both seemed very savage, but the mongoose would not bite the snake; he jumped over it. There had been two cobras in the cage during the night, both equally fierce, and striking each other and the mongoose; but the latter was uninjured. He was bitten once by the cobra rather severely on the head." JAMES W. EDMONDS

\section{HARTWIG'S SUBTERRANEAN WORLD*}

THE increasing demand for works of a semi-scientific character similar to that now under consideration, is in itself the most satisfactory proof that a desire for acquiring a more extended and accurate knowledge of the phenomena of Nature is gradually taking root within a

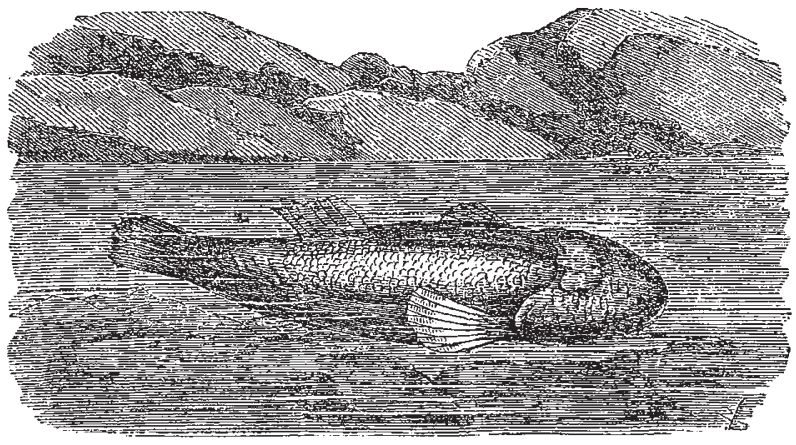

FIG. I.-Blind Fish (Anblyopsis spelaus)

class of society, which,'until of comparatively late years, had always contented itself with a very opposite style of literature. When it is observed, in many of the so-called popular scientific books, that accuracy has evidently been less * "The Subterranean World." By Dr. George Hartwig. (London: Longmans, Green, and Co.) 
carefully studied than what is termed sensational effect-a feature so characteristic of the period we live in-it is refreshing to find that Dr. Hartwig, in his description of the various phenomena of the subterranean world, has, without any such aid, succeeded admirably in conveying a vast amount of solid information, in so lucid and easy a style as to make even his unscientific readers quite interested, and likely to forget that he is treating of subjects usually considered as pertaining to the domain of dry Science. In so doing he seems also to have been assisted by having adopted a system of classification, or rather grouping, of the subjects which form his separate chapters, which, although not strictly scientific, is preferable in the present instance, as being more in accordance with popular notions.

The work, besides being well got up, is abundantly

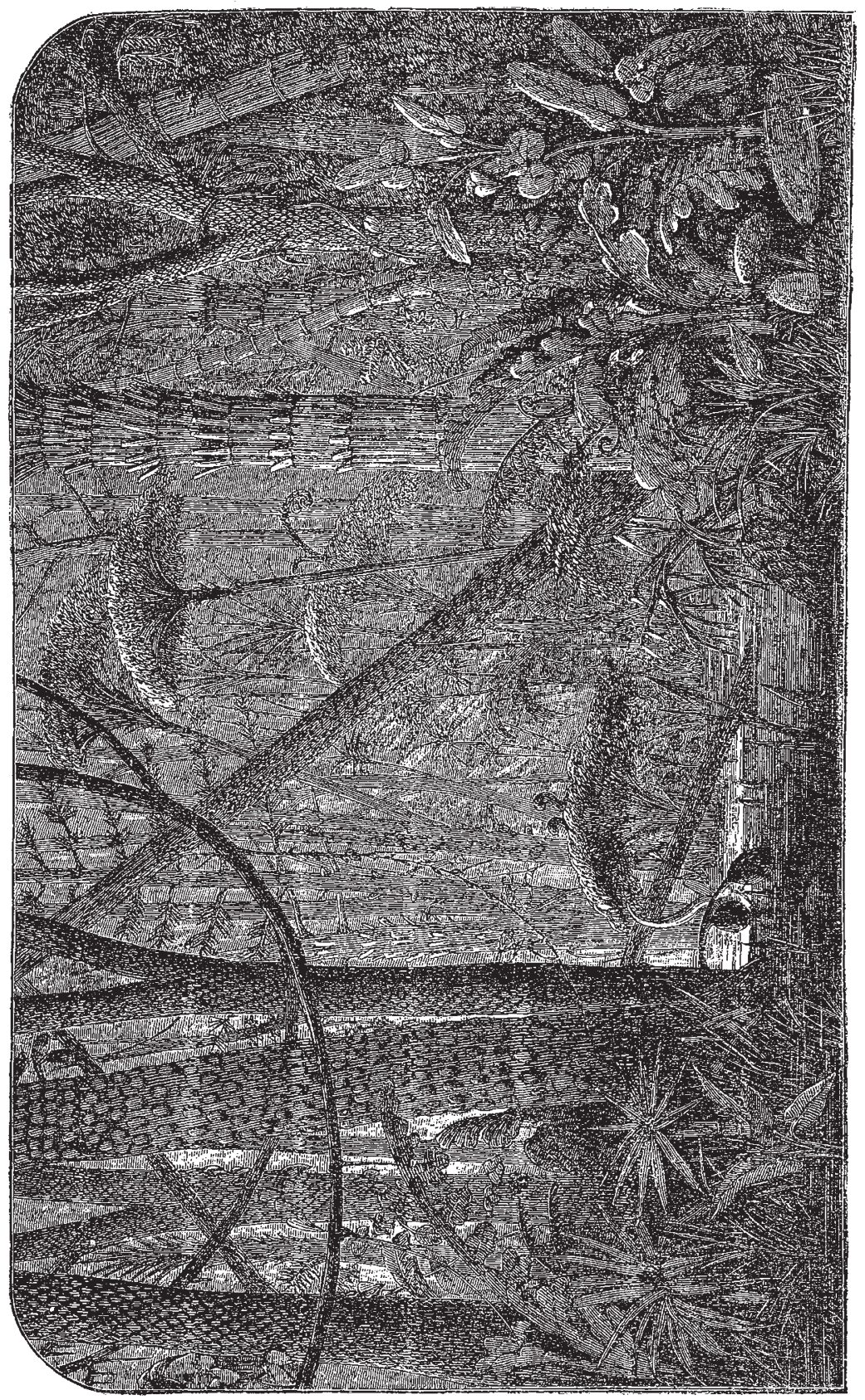

illustrated ; many of the woodcuts being of very superior character and execution, whilst the plates are, in general, good, and with one exception-that of the ideal view of the great earthquake at Lisbon in 1775 - they are free from that objectionable sensational or exaggerated character so observable in the illustrations of French works on popular Science, several of which have lately been renclered into English. The two maps indicating the distribution of coal and metallic deposits in Great Britain and the Americas respectively are not on a par with the rest, owing to errors of omission; thus, amongst others, neither the central lead-producing district of Wales, nor 
the Northampton iron district, are shown in the former ; nor have the auriferous deposits of Central America or British Columbia been indicated on the latter map.

In a work intended for the general British public, the temperature, when alluded to, should preferably have been stated in degrees of Fahrenheit's thermometer, since, al- though the scale of Celsius or centigrade is often made use of by men of science here, it will not be at all familiar to the majority of the readers of Dr. Hartwig's book, which it is to be hoped will have a very extended circulation. Several errors in the text might also be pointed out-as, for example, calling the usual Cornish ore or copper

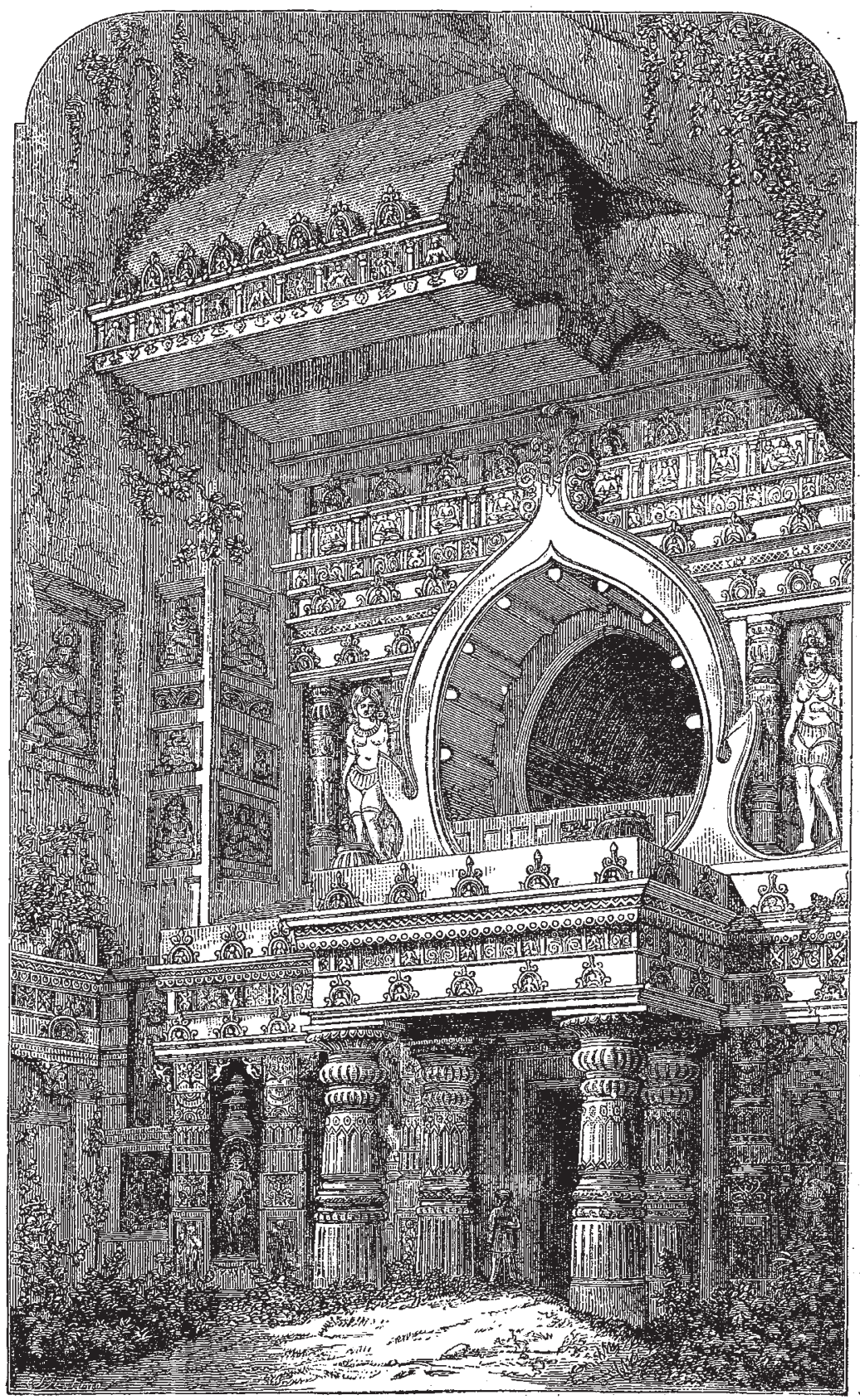

INDIAN ROCK-CUT TEMPLE: PORCH OF THE CHAITYA CAVE TEMPLE, AJUNTA

pyrites a bisulphuret of copper ; titanium is stated to be a metal of a copper red colour, \&c. ; but when the great extent of scientific ground over which the author travels in this book is taken into consideration, some allowance must be made, and it must fairly be admitted that the work, as a whole, is singularly free from serious errors, and we would recommend it strongly, in the belief that from its at once easy entertaining and instructive style, it will be sure to interest many in the study of these natural phenomena, to whom the very name of Science is at present associated with all that is dry and uninviting. D. $F$. 